\title{
Evaluation of the Adherence of Obstetricians to the International Guidelines for Dispensing Misoprostol and Oxytocin in Saad Abu Ella Maternity Hospital: A Retrospective Study
}

\author{
Mona Hashim Elbashir ${ }^{1}$, Safaa Badi ${ }^{2}$, Muhammad Abdou Abdulraheem ${ }^{2}$, and \\ Bashir Alsiddig Yousef ${ }^{3}$ \\ 'Department of Clinical Pharmacy, Faculty of Pharmacy, University of Khartoum, Al-Qasr Ave., \\ Khartoum 11111, Sudan \\ ${ }^{2}$ Department of Clinical Pharmacy, Faculty of Pharmacy, Omdurman Islamic University, Aboseid \\ Street, Khartoum 11111, Sudan \\ ${ }^{3}$ Department of Pharmacology, Faculty of Pharmacy, University of Khartoum, Al-Qasr Ave., \\ Khartoum 11111, Sudan
}

Corresponding Author: Bashir Alsiddig Yousef; Department of Pharmacology, Faculty of Pharmacy, University of Khartoum, Al-Qasr Ave., Khartoum 11111, Sudan.

Phone: +249155662037 Fax: +249183780696 Mobile: +249912932418 email:

bashiralsiddiq@gmail.com

Received 10 June 2020

Accepted 19 June 2020

Published 30 June 2020

Production and Hosting by Knowledge E

(c) Mona Hashim Elbashir et al. This article is distributed under the terms of the

Attribution License, which permits unrestricted use and redistribution provided that the original author and source are credited.

Editor-in-Chief:

Prof. Mohammad A. M. Ibnouf

\section{Abstract}

Background: Misoprostol and oxytocin are commonly prescribed drugs by obstetricians to induce labor and prevent postpartum hemorrhage. In Sudan, there is no national guideline for prescribing these drugs. Thus, the prescribers follow the international guidelines. Hence, our study aimed to evaluate the adherence of Sudanese obstetricians to the international guidelines for dispensing misoprostol and oxytocin.

Methods: A retrospective descriptive hospital-based study was performed at Saad Abu Ella hospital through their medical files archived in 2018 using a checklist designed by the researcher. Collected data were analyzed and presented in frequency tables using the statistical package for social sciences (SPSS).

Results: A total of 357 medical files were evaluated, about $50 \%$ of cases examined was in the 25-35 years age range, multigravida pregnant ladies were $62 \%$. General indications of oxytocin and/or misoprostol were induction of labor (17\%), postpartum hemorrhage prevention (PPH) after normal vaginal delivery (NVD) (30\%) and cesarean sections (32\%), evacuation of incomplete miscarriage (20\%), and termination of pregnancy (1\%). Compared to the guidelines, only $14 \%$ were given the recommended regimens for labor induction; $9.4 \%$ of women who had undergone NVD were given the recommended regimen to prevent $\mathrm{PPH}$. While, $57 \%$ and $43 \%$ of the cases with incomplete miscarriage and termination of pregnancy were given the recommended regimens, respectively. Based on the correct indication, total adherence was estimated to be $17 \%$.

Conclusions: Higher percentages of cases with incomplete miscarriage and intrauterine fetal death were given the recommended regimens to manage them. While, lower percentages of the participants were given the recommended regimens for labor induction and to prevent $\mathrm{PPH}$.

\section{S OPEN ACCESS}




\section{Introduction}

Labor is a rhythmic process of contraction and relaxation of the uterine muscles with progressive effacement and dilation of the cervix, leading to the expulsion of the fetus, placenta, and membranes through the birth canal $[1,2]$. This process can be natural or induced by stimulating the uterine contraction before the spontaneous onset of labor, with no complication [3]. In a life-threatening situation like severe antepartum hemorrhage and major cephalopelvic disproportion, the surgical cesarean section should be performed [4]. One of the major complications that may occur during labor is postpartum hemorrhage prevention (PPH) [2]. A pregnancy of up to 23 weeks can be terminated and an embryo weighing up to 500 grams is expelled, this is called an incomplete miscarriage, whereas, termination after 24 weeks of pregnancy and delivery with no signs of life is called intrauterine fetal death (IUFD) $[5,6]$.

Due to these complications, maternal mortalities continue to be one of the most serious and intractable health problems for women of reproductive age in low-income countries [7, 8]. Misoprostol and oxytocin are the most common drugs used to treat or prevent different complications related to pregnancy. Moreover, the ideal use of these drugs by following the guidelines has great value in managing the complication and reducing maternal mortality. In 2000, the World Health Organization (WHO) recommended the prophylactic use of a uterotonic immediately after delivery for all women, as part of the active management of the third stage of labor; oxytocin is recommended as a first-line drug [9]. For women without risk factors for postpartum hemorrhage delivering vaginally, oxytocin $10 \mathrm{IU}$ by intramuscular injection is the agent of choice for prophylaxis in the third stage of labor, a higher dose of oxytocin is unlikely to be beneficial. While, for cesarean section, oxytocin 5 IU by slow intravenous injection should be used [10]. In settings where the use of oxytocin is not feasible, $800 \mathrm{mcg}$ sublingual misoprostol might be a suitable first-line treatment of PPH (7).

For induction of labor, oral misoprostol appears to be less effective than vaginal misoprostol, regimen includes $50 \mathrm{mg}$ of misoprostol every $4 \mathrm{hr}$ PV to $200 \mathrm{mg}$ tablets every $6 \mathrm{hr}$ orally [11]. Medical management of incomplete abortion and miscarriage include the use of misoprostol $600 \mathrm{mcg}$ orally, which was included in the WHO 16th model list of essential medicines in 2009 and WHO priority medicines for mothers and children issued in 2011 [12]. The recommended dose of misoprostol for the treatment of incomplete abortion is $600 \mathrm{mcg}$ orally or $400 \mathrm{mcg}$ sublingually or $400-800 \mathrm{mcg}$ vaginal insert [13]. For the use of misoprostol for late IUFD, the dose should be adjusted according to gestational age; 200 mcg vaginal pessaries, sublingual, buccal every 4-6 
hr before 26 weeks of gestation, 100 mcg vaginal pessaries sublingual, buccal every 4 hr at 27 weeks or more up to $24 \mathrm{hr}$ [13].

Oxytocin is superior to misoprostol in the prevention of postpartum hemorrhage (evidence level 1++), appraisal of evidence from the Cochrane Reviews together with consideration of standard practice in the UK suggests that for a woman delivering vaginally, oxytocin $10 \mathrm{IU}$ by intramuscular injection is the regimen of choice for prophylaxis in the third stage of labor (evidence level 1+) [10]. Misoprostol is not preferred to injectable uterotonic (oxytocin and ergometrine) for the management of third stage of labor [10]. There is no added benefit of offering misoprostol as an adjunct treatment for PPH in women who have received oxytocin during the third stage of labor. Where oxytocin is available and is used in the management of the third stage of labor, oxytocin alone should be used in preference to adjunct misoprostol for the management of PPH [14].

Since there is no national protocol for the use of oxytocin and misoprostol in Sudan, and in order to assess the prescribing behavior of obstetricians, the adherence of prescribers for international guidelines, Royal College of Obstetrics and Gynecology (RCOG) in Saad Abu Ella specialist hospital during 2018 was assessed.

\section{Methods and Materials}

\subsection{Study setting}

This study was a retrospective descriptive cross-sectional hospital-based study. The study was conducted at the Saad Abu Ella's maternity hospital. The data were collected from the records of the patients who attended the hospital with normal vaginal deliveries (NVDs), emergency and elective cesarean sections C/S, missed miscarriage, and IUFD, between January and December 2018.

\subsection{Inclusion criteria}

The target population was pregnant women with NVDs, emergency and elective cesarean sections $\mathrm{C} / \mathrm{S}$, missed miscarriage, and IUFD attending the hospital from January to December 2018. 


\subsection{Exclusion criteria}

Participants with incomplete records, pregnancy termination and evacuations done during the study period were excluded from the study.

\subsection{Study sample}

Data were collected from the records of the patients by using a simple random sampling technique. The total number of pregnant women with NVDs, emergency (Em-CS) and elective cesarean sections (EI-CS), missed miscarriage, and IUFD who attended to the hospital during the study period was 3,320.

Sample size was calculated by using Slovin's equation [15]:

$$
n=\frac{N}{1+N(e) 2}=n=\frac{3320}{1+3320(0.05) 2}, n=356.9=357
$$

Where $N=$ total target population attending the center during the study period; $n=$ sample size, and e = margin of error $(0.05)$ at $95 \%$ confidence level.

\subsection{Data collection tool}

The data was collected using a predesigned standardized and structured checklist, which was developed by the researcher. The data collection tool included patients' information such as the drugs used, indication, dose, and the outcomes, which were documented in medical records. In order to measure the adherence of Sudanese obstetricians, all collected information about used drugs were compared with the recommendations of the Royal College of Obstetrics and Gynecology (RCOG) guidelines.

\subsection{Statistical analysis}

Data were analyzed using the IBM Statistical Package for Social Sciences [SPSS] for Windows, Version 23.0 software [Armonk, NY: IBM Corp]. Data are demonstrated as tables for the descriptive statistics (frequency tables). 


\subsection{Socio-demographic and clinical data of the participants}

Out of the 357 included cases, 49\% were aged 25-35 years; 32\% were pregnant women with cesarean sections; $30 \%$ were women who underwent normal vaginal deliveries, of which $17 \%$ received drugs to facilitate the labor; $20 \%$ of the participants were pregnant women suffering from an incomplete miscarriage; and only $7 \%$ had intrauterine, vaginal deaths that needed termination. In all deliveries, the primigravida was $38 \%$ of all deliveries, while multigravida was found in $62 \%$ of all deliveries (Table 1 ).

By classifying the types of delivery for primigravida pregnant ladies, about $58 \%$ of all cases were normally delivered, $29 \%$ were delivered by Em-CS, and finally, only $13 \%$ were delivered by EI-CS. As per the multigravida pregnant ladies' files, $49 \%$ had a normal delivery, 34\% delivered by El-CS, and only 17\% underwent Em-CS. The different indications that led to surgical intervention ( $n=123)$, either an EI-SC or an Em-CS were evaluated, in which, $32.5 \%$ of them was due to a previous cesarean scar, $16.2 \%$ was due to fetal distress, $13.8 \%$ was due to failure of the fetus progression, and $12.1 \%$ was due to the breech presentation (Table 2).

\subsection{Regimens used for the induction of labor}

Of all NVD cases ( $n=117$ cases), about 53 (45.2\%) cases did not use any drug(s) to facilitate the labor and had NVD, while the other 64 (54.7\%) cases used different regimen(s) to facilitate the vaginal labor, 47 (73.4\%) of them successfully ended in NVD and $17(26.6 \%)$ cases failed to progress to NVD and underwent Em-SC. In all 64 cases, only in 9 (14\%), the recommended regimen of adding oxytocin $5 \mathrm{IU}$ to an isotonic solution was used, while in the 41 (64\%) oxytocin 2 IU was used, 30 (73\%) of them succeeded to undergo NVD while others failed. On the other hand, for misoprostol, no case received the recommended induction dose (50-100 mcg vaginal pessary, 200 mcg Oral) (Table 3)

\subsection{Regimens used after NVD and after CS as PPH prophylaxis}

Post NVD, different regimens were given as PPH prophylaxis agent, as shown in Table 4; the most used regimen for PPH prophylaxis was oxytocin 20 IU given as 10 IU by intramuscular and $10 \mathrm{IU}$ by intravenous routes of administrations. The recommended doses after CS is oxytocin $5 \mathrm{IU}$, which was not seen in all files surveyed. On the contrary, the most used regimen was the combination therapy of misoprostol four tablets (given 
as one tablet sublingual and three tablets per rectum) in 75 (61\%) participants and oxytocin $30 \mathrm{IU}$ (given as $10 \mathrm{IU}$ intravenous injection and $20 \mathrm{IU}$ given via intravenous infusion) in 20 (16.2\%) participants (Table 4).

\subsection{Adherence of prescribers to guidelines}

The adherence of prescribers to each uterotonic indication was evaluated compared to the recommended RCOG guidelines. We found that only $14 \%$ of the cases were given the recommended regimens for labor induction. Of the participants who delivered through NVD, only 9.4\% were given the recommended regimen and doses to prevent PPH, while, on the other hand, no one among those who delivered through caesarian section was given the recommended regimens to prevent PPH regarding. However, 57\% and $43 \%$ of the cases with incomplete miscarriage and IUFD were given the recommended regimens, respectively (Table 5). The total adherence was calculated by dividing the total correct indications by the total indications, and it was estimated to be $17 \%$.

TABLE 1: Socio-demographic and clinical characteristics of the participants ( $n=357)$

\begin{tabular}{l|c} 
Number (\%) & Variable \\
Age of the participants & $95(27 \%)$ \\
\hline $15-25$ years & $175(49 \%)$ \\
$25-35$ years & $87(24 \%)$ \\
\hline $35-45$ years & \\
\hline Indications for misoprostol and oxytocin & $64(17 \%)$ \\
\hline Induction of labor & $117(30 \%)$ \\
\hline Normal vaginal delivery (NVD) & $123(32 \%)$ \\
\hline Cesarean section & $76(20 \%)$ \\
Incomplete miscarriage & $7(1 \%)$ \\
\hline Intra uterine fetal death & \\
\hline Gravida ( $n=240)$ & $90(38 \%)$ \\
Primigravida & $150(62 \%)$ \\
\hline Multigravida & \\
\hline Type of delivery (Primigravida) $(n=90)$ & $52(58 \%)$ \\
NVD & $26(29 \%)$ \\
\hline Emergency Caesarian Section (Em-SC) & $12(13 \%)$ \\
\hline Elective Caesarian Section (El-SC) & \\
\hline Type of delivery (Multigravida) $(n=150)$ & $25(17 \%)$ \\
\hline NVD & $51(34 \%)$ \\
\hline Em-SC & \\
\hline El-SC) & \\
\hline
\end{tabular}


TABLE 2: Different indications for emergency (Em-CS) and elective cesarean section (EI-CS) $(n=123)$

Indication
Breech presentation
Uterine fibroid
Previous cesarean scar
Refusal of VBAC
Fetal distress
Failure To Progress
Sizeable baby
Severe preeclampsia
Pregnancy induced hypertension
Abruptio placentae
Oligohydramnios
Polyhydramnios
Chorioamnionitis
Precious baby
Fetal Bradycardia
Twin baby
Total

\begin{tabular}{|c|}
\hline Number (\%) \\
\hline $15(12.2 \%)$ \\
\hline $1(0.8 \%)$ \\
\hline $49(39.8 \%)$ \\
\hline $5(4.1 \%)$ \\
\hline $20(16.3 \%)$ \\
\hline $17(13.8 \%)$ \\
\hline $2(1.6 \%)$ \\
\hline $3(2.5 \%)$ \\
\hline $2(1.6 \%)$ \\
\hline $2(1.6 \%)$ \\
\hline $1(0.8 \%)$ \\
\hline $1(0.8 \%)$ \\
\hline $1(0.8 \%)$ \\
\hline $1(0.8 \%)$ \\
\hline $1(0.8 \%)$ \\
\hline $2(1.6 \%)$ \\
\hline $123(100 \%)$ \\
\hline
\end{tabular}

\begin{tabular}{c}
\hline Em-CS \\
6 \\
- \\
- \\
- \\
\hline 20 \\
17 \\
- \\
\hline 3 \\
2 \\
2 \\
- \\
- \\
- \\
\hline- \\
\hline 1 \\
\hline $51(41.5 \%)$ \\
\hline
\end{tabular}

\begin{tabular}{|c|c|}
\hline EI-CS & 8 \\
1 & 49 \\
\hline 5 & - \\
\hline- \\
\hline 2 \\
\hline- \\
\hline- \\
- \\
\hline 1 \\
\hline 1 \\
\hline 1 \\
\hline 1 \\
\hline- \\
\hline 2 \\
\hline $72(58.5 \%)$ \\
\hline
\end{tabular}

TABLE 3: Different regimen(s) used to induce labor among participants ( $n=64$ )

Regimen
Oxytocin $2 \mathrm{IU}$
Oxytocin $4 \mathrm{IU}$
Oxytocin $5 \mathrm{IU}$
Oxytocin $10 \mathrm{IU}$
Oxytocin $20 \mathrm{IU}$
Misoprostol 1 tab vaginally
Misoprostol 4 tabs Orally
Misoprostol 3 tabs Oral + Oxytocin $2 \mathrm{IU}$
Misoprostol 4 tabs Oral +Oxytocin $4 \mathrm{IU}$
Total

\begin{tabular}{|c|}
$\begin{array}{c}\text { Number of cases } \\
(\%)\end{array}$ \\
\hline $41(64 \%)$ \\
\hline $1(1.6 \%)$ \\
\hline $9(14 \%)$ \\
\hline $1(1.6 \%)$ \\
\hline $3(4.7 \%)$ \\
\hline $3(4.7 \%)$ \\
\hline $3(4.7 \%)$ \\
\hline $2(3.1 \%)$ \\
\hline $1(1.6 \%)$ \\
\hline $64(100 \%)$ \\
\hline
\end{tabular}

\begin{tabular}{|c|}
$\begin{array}{c}\text { Number of } \\
\text { Successful cases }\end{array}$ \\
\hline 30 \\
\hline 0 \\
\hline 7 \\
\hline 1 \\
\hline 3 \\
\hline 3 \\
\hline 0 \\
\hline 2 \\
\hline 1 \\
\hline $47(73.4 \%)$ \\
\hline
\end{tabular}

\begin{tabular}{|c|}
\hline $\begin{array}{c}\text { Number of } \\
\text { failure* }\end{array}$ \\
\hline 11 \\
1 \\
\hline 2 \\
\hline 0 \\
\hline 0 \\
\hline 0 \\
\hline 3 \\
0 \\
\hline 0 \\
\hline $17(26.6 \%)$ \\
\hline
\end{tabular}

${ }^{*}$ Those for whom the treatment failed were directly indicated to emergency caesarian section

\section{Discussion}

Maternal mortality remains a major concern, particularly in developing countries, as there are around 450 maternal deaths per 100,000 live births versus only 9 in developed countries [16]. Therefore, proper management of the complications has great importance in reducing the mortality rate. The current study was conducted to evaluate the adherence of Sudanese obstetricians to international guidelines for dispensing 
TABLE 4: Different regimens used after normal vaginal delivery (NVD) and after caesarian section (CS) as postpartum hemorrhage prophylaxis $(\mathrm{PPH})$

\begin{tabular}{|c|c|c|}
\hline & Regimen & Number (\%) \\
\hline \multirow{11}{*}{$\begin{array}{l}\text { Regimens used for PPH prophylaxis in } \\
\text { NVD }\end{array}$} & No Drug & $9(7.7 \%)$ \\
\hline & Misoprostol 4 tabs & 5 (4.2\%) \\
\hline & Misoprostol 4 tabs + Oxytocin $20 \mathrm{IU}$ & $3(2.6 \%)$ \\
\hline & Misoprostol 4 tabs + Oxytocin $30 \mathrm{IU}$ & $3(2.6 \%)$ \\
\hline & Misoprostol 3 tabs + Oxytocin $20 \mathrm{IU}$ & $2(1.7 \%)$ \\
\hline & Misoprostol 3 tabs + Oxytocin $30 \mathrm{IU}$ & 1 (0.9\%) \\
\hline & $\begin{array}{l}\text { Misoprostol } 4 \text { tabs + Oxytocin } 20 \\
\text { IU+ Ergometrine }\end{array}$ & 1 (0.9\%) \\
\hline & Oxytocin $10 \mathrm{IU}$ & $11(9.4 \%)$ \\
\hline & Oxytocin $20 \mathrm{IU}$ & 76 (64.9\%) \\
\hline & Oxytocin $30 \mathrm{IU}$ & $6(5.1 \%)$ \\
\hline & Total & 117 (100\%) \\
\hline \multirow{10}{*}{$\begin{array}{l}\text { Regimens used in PPH prophylaxis in CS } \\
\text { delivery }\end{array}$} & Oxytocin $10 \mathrm{IU}$ & $2(1.6 \%)$ \\
\hline & Oxytocin $20 \mathrm{IU}$ & $4(3.2 \%)$ \\
\hline & Oxytocin $30 \mathrm{IU}$ & 20 (16.2\%) \\
\hline & Misoprostol 4 tabs & 7 (5.7\%) \\
\hline & Misoprostol 3 tabs + Oxytocin $30 \mathrm{IU}$ & $1(0.8 \%)$ \\
\hline & Misoprostol 4 tabs + Oxytocin $20 \mathrm{IU}$ & $8(6.5 \%)$ \\
\hline & Misoprostol 4 tabs + Oxytocin $30 \mathrm{IU}$ & 75 (61\%) \\
\hline & Misoprostol 4 tabs + Oxytocin $40 \mathrm{IU}$ & $4(3.2 \%)$ \\
\hline & Misoprostol 4 tabs + Oxytocin $50 \mathrm{IU}$ & $2(1.6 \%)$ \\
\hline & Total & $123(100 \%)$ \\
\hline
\end{tabular}

the most commonly used drug for these complications at a specialized hospital. Half of the studied women were aged between 25 and 35 years and $62 \%$ of them were multigravida. These drugs were mainly indicated for cesarean section, normal vaginal delivery, incomplete miscarriage, induction of labor, or intrauterine death. For the induction of labor, 55\% of NVDs used these drugs to facilitate labor; of them, about 73\% resulted in successful-NVD, while $27 \%$ suffered a failure to progress the labor resulting in Em-CS. The most used dose of oxytocin was $2 \mathrm{IU}$ (64\%), usually added to $500 \mathrm{ml}$ normal saline drip given at different rates of 15,16 , or $20 \mathrm{drop} / \mathrm{min}$, the recommended dose is $5 \mathrm{IU}$ added to $500 \mathrm{ml}$ of isotonic solution. Most of the files lack information on the infusion rate to detect the actual drug received. Besides that, the facility has no pump to adjust the dose of oxytocin, which leads to fluctuation in the dose given.

Side effects of oxytocin are dose-related, including fetal heart rate changes and uterine tachysystole, which may result in abruptio placentae and uterine rupture [17]. Rest of 
TABLE 5: Different regimens used for incomplete miscarriage evacuation and intra uterine fetal death.

\begin{tabular}{|l|l|c|}
\hline $\begin{array}{l}\text { Regimens used for incomplete } \\
\text { miscarriage evacuation }\end{array}$ & Regimen & Number (\%) \\
\hline & Misoprostol 2 tabs vaginally & $4(5.3 \%)$ \\
\hline & Misoprostol 3 tabs vaginally & $2(2.6 \%)$ \\
\hline & Misoprostol 2 tabs orally & 7 tabs vaginally \\
& Misoprostol 3 tabs orally & $4(5.3 \%)$ \\
\hline Regimens used for intra uterine fetal & Misoprostol 4 tabs orally & $30(39.5 \%)$ \\
\hline death & Motal & $29(38.1 \%)$ \\
\hline & Misoprostol $1 / 2$ tab vaginally/4 h & $76(100 \%)$ \\
\hline & Misoprostol 1 tab vaginally/6 h & $1(14.2 \%)$ \\
\hline & Misoprostol 4 tabs orally & $2(28.6 \%)$ \\
\hline & Misoprostol 4 tabs + Oxytocin 40 IU & $2(28.6 \%)$ \\
\hline & Total & $7(100 \%)$ \\
\hline
\end{tabular}

the regimen used exceeded the suggested doses by RCOG, and the increase in uterus contraction may lead to fetal distress due to a decrease in blood supply and oxygen ending the delivery to an Em-CS in about $27 \%$ of all cases. Many obstetricians used unnecessarily high doses of oxytocin, causing excessive uterine activity and believed that intervention was not needed unless there were unnecessary changes in fetal heart rate [18]. Oxytocin administered as an intravenous bolus of $10 \mathrm{IU}$ was reported to induce chest pain, transient profound tachycardia, and hypotension, and ECG changes suggestive of myocardial ischemia $[19,20]$. Also, oxytocin misuse increases the risk of ruptured uterus, fetal asphyxia, and fetal death [21]. Oxytocin augmentation had been associated with neonatal sepsis, fetal distress, postpartum hemorrhage, uterine rupture, and a higher incidence of cesarean section [13].

Misoprostol is used to induce labor in different doses alone or in combination with oxytocin, the most effective route of administration is through vagina [22, 23], yet different regimens include oral route as well. Also, the dose of misoprostol in $9 \%$ of the cases were above the recommended dose. When used in combination with oxytocin, oxytocin should not be commenced until $4 \mathrm{hr}$ of misoprostol last dose [24], which is not observed in doctor's orders in files. The doses used to induce labor were way above the recommended dose; 50 mcg PV [ 25 mcg PV by RCOG], 3-4 tabs orally [200 mcg PO,17]. In Nigeria, a study revealed that the mean induction to the vaginal delivery interval was significantly shorter in the misoprostol user compared to the oxytocin users; in addition, misoprostol is more effective in reducing the complications such as PPH when compared to the oxytocin. 
The most used PPH prophylactic dose post-normal vaginal delivery was 20 IU of oxytocin (65\%) given as $10 \mathrm{IU}$ intravenously and $10 \mathrm{IU}$ intramuscularly, the recommended dose of oxytocin by RCOG is 10 IU given by I.M route [22, 23], which was achieved only by $9.4 \%$ of all cases. As results shows, there none of the cases used the recommended dose of oxytocin post-cesarean delivery (5 IU) $[22,23]$. Six regimens used a different combination of both misoprostol and oxytocin, which does not exist in any protocol unless actual hemorrhage occurs. The most used regimen (61\% of all cases) is a combination of misoprostol 4 tablets and oxytocin $30 \mathrm{IU}$ given as 1 tablet sublingually, 3 tablets rectally beside $10 \mathrm{IU}$ oxytocin intravenously and $20 \mathrm{IU}$ through infusion postoperatively which is considered as an overdose because the use of misoprostol is not associated with any significant reduction in the incidence of $\mathrm{PPH}$; of all uterotonic, ergometrine is the drug of choice in PPH prevention followed by oxytocin [26, 27]. Only one case used ergometrine with other uterotonic as PPH prevention agent, and that case was considered to be of high PPH risk (twin baby). The use of misoprostol as PPH prevention agent is not preferred to conventional injectable uterotonic [10].

Regarding doses of missed miscarriage, the guideline has many options for misoprostol ranging from $400 \mathrm{mcg}$ to $800 \mathrm{mcg}$ as a vaginal insert to $600 \mathrm{mcg}$ orally, so adherence of prescribers to the guideline was about $56.6 \%$. The success of medical treatment was 39.5\% of all cases, and the rest needed surgical intervention. Use of misoprostol for second-trimester termination of pregnancy has been associated with uterine rupture, particularly when combined with oxytocin infusion. In a report of 803 women admitted to hospital with abortion complications in Rio de Janeiro, 458 reported using misoprostol. There were three deaths (two from sepsis and one from the uterine rupture at 16 weeks of gestation) following self-medication with misoprostol. Therefore, the misoprostol dosage used in the second trimester needs to be limited, and oxytocin infusion should not commence within $6 \mathrm{hr}$ of administering misoprostol [28]. Regarding IUFD, 57\% of cases used an overdose regardless of the guideline's recommendation. The concurrent use of misoprostol with oxytocin was reported to potentiate misoprostol effect; only two cases used this regimen $[22,23]$.

Generally, the prescriber's adherence to guidelines in the current study was achieved only in 17\% of all cases. A study conducted in seven countries in 2005-2006 reported that the active management of the third stage of labor was only implemented correctly in $0.5-32 \%$ of deliveries observed [29], hence, adherence to guidelines is a major problem facing many countries.

This study is not without limitations; first, the study was conducted at only one center. Therefore, we cannot generalize the finding of this study to the whole of Sudan. 
Second, upon data collection, many missed data were observed, such as infusion rate and adverse effects, which also affect the measurement of the adherence. However, even with these limitations, our findings are valuable, as it highlights the importance of following the guidelines. Thus, further multi-central studies are highly recommended to evaluate adherence nationally.

The study concludes that higher percentages of cases with incomplete miscarriage and IUFD were given the recommended regimens of misoprostol or oxytocin to manage them, while lower percentages of the participants were given the recommended regimens for labor induction and to prevent postpartum hemorrhage. Furthermore, the overall calculated adherence for the obstetricians was found to be low.

\section{Ethical Consideration}

The study was approved by the Ethical Committee of the Faculty of Pharmacy, University of Khartoum. The additional official agreement was obtained from Saad Abul-Ella Teaching Hospital to check the medical record; all medical records were coded ensuring confidentiality throughout the study.

\section{Acknowledgement}

The authors would like to appreciate all members of Saad Abu Ella hospital for their collaboration.

\section{Conflicts of Interest}

There are no conflicts of interest.

\section{Author Contribution}

Concept, design, and literature search were done by Mona Hashim Elbashir and Dr. Bashir Alsiddig Yousef. Data were collected by Mona Hashim Elbashir and analyzed by Safaa Badi and Muhammad Abdou Abdulraheem. Dr. Bashir Alsiddig Yousef drafted the manuscript and critically revised the important intellectual content. All authors gave their approval to publish the final version of the manuscript. 


\section{References}

[1] Spinner, M. R. (1978).Maternal-infant bonding. Can Fam Physician. 1978;24:1151-3.

[2] Jacob A. A comprehensive textbook of Midwifery and Gynecological Nursing, 3rd ed. London: Jaypee Brothers Medical Publishers (P) Ltd, 2012; 133-141.

[3] ACOG Committee on Practice Bulletins - Obstetrics. (2009). ACOG Practice Bulletin No. 107: Induction of labor. Obstetrics \& Gynecology, vol. 114, no. 2, pt 1, pp. 386-397.

[4] Stanton, C. and Ronsmans, C. (2008). Caesarean birth as a component of surgical services in low- and middle-income countries. Bulletin of the World Health Organization, vol. 86, no. 12, A.

[5] Murphy FA, Lipp A, Powles DL. Follow-up for improving psychological well being for women after a miscarriage. Cochrane Database Syst Rev. 2012;(3):CD008679.

[6] Duckworth, H. L. and Stanley, K. P. (2011). Induction of labour of intrauterine fetal death 24/40: audit of a UK teaching hospital's practice over 1 year, prior to introduction of recent RCOG green-top guideline no. 55. Archives of Disease in Childhood - Fetal and Neonatal Edition, vol. 96, Fa89.

[7] Tsu VD, Shane B. New and underutilized technologies to reduce maternal mortality: call to action from a Bellagio workshop. Int J Gynaecol Obstet. 2004;85(Suppl 1):S83s93.

[8] Hill S, Yang A, Bero L. Priority medicines for maternal and child health: a global survey of national essential medicines lists. PLoS One. 2012;7:e38055.

[9] WHO. (2003). Pregnancy, Childbirth, Postpartum, and Newborn Care: A Guide For Essential Practice. WHO.

[10] No G-tG. (2016). Prevention and management of postpartum haemorrhage. BJOG, vol. 124, pp. e106-e149.

[11] National Collaborating Centre for Women's and Children's Health (UK). (2008). Induction of Labour. London: RCOG Press. (NICE Clinical Guidelines, No. 70.). Retrieved from: https://www.ncbi.nlm.nih.gov/books/NBK53620/

[12] WHO. (2018). Medical Management of Abortion: Pocket Guide. WHO.

[13] Morris, J. L., Winikoff, B., Dabash, R., et al. (2017). FIGO's updated recommendations for misoprostol used alone in gynecology and obstetrics. International Journal of Gynecology \& Obstetrics, vol. 138, pp. 363-366.

[14] WHO. (2012). WHO Recommendations For the Prevention and Treatment of Postpartum Haemorrhage. WHO.

[15] Galero-Tejero, E. (2011). A Simplified Approach to Thesis and Dissertation Writing, pp. 43-44. Mandaluyong City: National Book Store. 
[16] WHO. (2011). Priority Medicines For Mothers and Children 2011. WHO.

[17] Olefile KM, Khondowe O, M'Rithaa D. Misoprostol for prevention and treatment of postpartum haemorrhage: A systematic review. Curationis. 2013;36(1):1-10.

[18] Simpson KR, James DC. Effects of oxytocin-induced uterine hyperstimulation during labor on fetal oxygen status and fetal heart rate patterns. Am J Obstet Gynecol. 2008;199(1):34.e1-5.

[19] Weeks AD, Fiala C, Safar P. Misoprostol and the debate over off-label drug use. BJOG. 2005;112(3):269-72.

[20] Allen R, O'Brien BM. Uses of misoprostol in obstetrics and gynecology. Rev Obstet Gynecol. 2009;2(3):159-68.

[21] Tang OS, Gemzell-Danielsson K, Ho PC. Misoprostol: pharmacokinetic profiles, effects on the uterus and side-effects. Int J Gynaecol Obstet. 2007;99(suppl 2):S160_ S167.

[22] RCOG. (2008). Induction of labour (NICE Clinical Guidelines, No. 70). London: RCOG Press.

[23] McCarthy FP, Kenny LC. Induction of labour. Obstetrics, Gynaecology \& Reproductive Medicine. 2014;24(1):9-15.

[24] Stanton C, Armbruster D, Knight R, Ariawan I, Gbangbade S, Getachew A, et al. Use of active management of the third stage of labour in seven developing countries. Bulletin of the World Health Organization. 2009;87(3):207-15.

[25] Ezechi OC, Loto OM, Ezeobi PM, Okogbo FO, Gbajabiamila T, Nwokoro CA. Safety and efficacy of misoprostol in induction of labour in prelabour rupture of fetal membrane in Nigerian women: a multicenter study. International Journal of Reproductive BioMedicine. 2008;6(3):83-0.

[26] Güngördük K, Olgaç Y, Gülseren V, Kocaer M. Active management of the third stage of labor: A brief overview of key issues. Turk J Obstet Gynecol. 2018;15(3):188-92.

[27] Maughan KL, Heim SW, Galazka SS. Preventing postpartum hemorrhage: managing the third stage of labor. Am Fam Physician. 2006;73(6):1025-8.

[28] Costa, S. H. and Vessey, M. P. (1993). Misoprostol and illegal abortion in Rio de Janeiro, Brazil. Lancet, vol. 341, pp. 1258-1261.

[29] Stanton, C., Armbruster, D., Knight, R., et al. (2009). Use of Active Management of the Third Stage of Labour in Seven Developing Countries. SciELO Public Health. 